\title{
ENSAIO DE PALATABILIDADE E DIGESTIBILIDADE COM RAÇÕES COMERCIAIS PARA EQÜINOS EM REGIME DE ESTABULAÇĀO FORÇADA. (NOTA PRÉVIA)
}

\section{PALATABILITY AND DIGESTIBILITY OF HORSE COMMERCIAL DIETS STABLING IN CONDITION}

\author{
Ckero Telles de Nogueira CRAVO'; FIavo PRADA
}

\begin{abstract}
RESUMO
Estudou-sc, em eqüinos a palatabilidade e digestibilidade da raçăo comercial em regime de estabulaçăo forçada. Os animais estabulados receberam ração contendo $4 \mathrm{~g}$ de óxido crômico por dia de experimento. As excreçðes colhidas quantilativamente em períodos de 24 horas compuseram as amostras representativas $\mathrm{c}$ do total de 5 dias. A ração foi bem aceita pelos animais que consumiram 6 kilos/dia durante 18 dias experimentais. Os coeficientes de digestibilidade médios $(88,35$ e 89.59) revelaram um alto índice de aproveitamento da raçāo.
\end{abstract}

UNITERMOS: Alimentos, digestibilidade; Ração animal; Cavalos

\section{INTRODUÇĀO}

A etapa inicial obrigatória e importante, visando o aproveitamento de uma raçāo, é sem dúvida o conhecimento de sua palatabilidade e composiçăo química. Estes dados năo traduzem exatamente o valor do alimento, como fonte de principios nutritivos, mas informam sobre a utilizaçăo ou năo do mesmo para determinadas espécies.

Por outro lado, objetivando-se informaçðes mais detalhadas sobre o aspecto nutritivo, necessário e importante é procederse à determinação da digestibilidade aparente de cada componente conhecido, pela análise química inicial.

Na literatura nacional såo encontradas poucas investigaçðcs a respeito da avaliação da digestibilidade de raçðes para cqüinos, muito embora o Brasil possua cerca de $14 \%$ dos equiinos do rebanho mundial.

O objetivo do presente trabalho é o de verificar a possibilidade de utilizaçăo de raçåo comercial para eqủinos, particularmente quanto à sua palatabilidade e digestibilidade, no scntido de suprir parcial ou totalmente a necessidade alimentar de forragens verdes. A viabilidade desse procedimento altemativo reverte-se de grande importância quanto à possibilidade de prevençāo de algumas afecçóes patológicas comuns nos equíinos (cólicas), nas épocas de estiagem prolongada, quando a vegetaçāo dos pastos é escassa.

\section{REVISĀO DA LITERATURA}

O desenvolvimento da determinaçăo da digestibilidade aparente iniciou-se com o método convencional clássico. Apesar de muito trabalho, por exigir rigoroso controle do alimento ingerido e das fezes excretadas, foi mundialmente empregado nas mais variadas espécies. As dificuldades na recolha c perda de amostras, fizeram com que os observadores empregasisem bolsas colctoras. Assim FRIEND e NICHOLSON" (1965) foram os primeiros a utilizarem para equitinos este método de collheita.

O emprego do óxido crômico, como substância índice para a detcrminaça da digestibilidade aparente foi proposia px Fedin cm 1918. Este trabalho so teve divulgacăo a parir de 1944, quan(k) o autor divulgou $\mathrm{cm}$ língua inglesa as suas observacous F.DIN ct al ${ }^{4}$ (1944). No Brasil o pioneiro em csludos com óxido cromico foi ANDREASI', que publicou seus trabalhos em ratos em 1955.

ITURBIDE $^{10}$ (1967), em ampla revisăo bibliográfica, dessas formas de administraçăo, observa que a maioria dos autores opta pela cápsula de gelatina.

Outros autores como HINTZ; LOY9 (1966); HINTZ et al." (1971), com pôneis, OLSSON ${ }^{13}$ (1949) e PULSE e BEKER ${ }^{14}$ (1971) em cquiinos utilizaram 6xido crômico em seus ensaios.

Quanto às quantidades diárias KNAPKA et al." (1967) administraram $5 g$ ao dia, divididas em duas porçóes iguais.

VEIGA et al." (1974) ministraram a raçæo base de $0,136 \%$ sobre a matéria seca (M.S.).

\section{MATERIAL E MÉTODO}

\section{Animais}

Foram utilizados para o ensaio, 2 animais adulıs", um macho castrado e uma femea, sem raça definida, de pesos bem próximos: 167 quilos para 0 animal $n^{\circ} 1$ e 193 quilos para o animal $n^{\circ} 2$.

\section{Instalações}

Foram utilizadas duas baias de parte externa do HOVET**,

1-Médico Veterinário - Sul Mineira Alimentos S.A.

2-Professor Titular - Faculdade de Medicina Velerinária e Zootecnia da USP

- Unidade Esstatística Experimental segundo GOMES' (1963)

- Hospital Veterinánio da Faculdade de Modicina Veterinána e Zootecnia da USP 
medindo $2,5 \mathrm{~m} \times 3,5 \mathrm{~m}$ com pisos e paredes cimentados. Os pisos foram recobertos com cama de serragem. Apresentavam ainda dois cochos para água e alimento.

\section{Raçāo***}

A raçăo comercial utilizada no experimento apresentou os níveis de garantia conforme Tab. 1.

\section{TABELA 1}

Composiçắo quimica da raçăo em (\%) - niveis de garantia. Săo Paulo 1992.

\begin{tabular}{lc}
\hline Componentes brutos & Sobre M. Úmida \\
\hline Maléria Seca & 88,0 \\
Protelna Bruta (min.) & 11,0 \\
Extrato Eléreo (min) & 2,0 \\
Fibra Bruta (máx.) & 13,0 \\
Matéria Mineral (máx.) & 13,0 \\
Cálcio (máx.) & 1,5 \\
Fósforo (min.) & 0,5 \\
\hline
\end{tabular}

O alimento em questăo era formado por dois "pellets", um com alfafa previsada em "fibras longas" e prensada outro com os componentes (proteínas, carboidratos, vitaminas e minerais) normais de uma raçăo. Apresentava grăos de triguilho e cevada integral, isto com a finalidade de equilibrar os vários nutrientes necessários para o bom desenvolvimento orgànico.

As porcentagens eram as seguintes: milho quirera $17 \%$, alfafa pellets $8 \%$, triguilho gråos $15 \%$, cevada grăos $20 \%$, pellets cavalo**** $35 \%$, melaço líquido $5 \%$

\section{Alimentaçāo}

Com a finalidade de adaptar os animais às condiçōes adversas (estabulação, modificaçăo da raçăo) o periodo pré-preliminar e experimental totalizou 18 dias. Como o alimento precisava ser controlado e não seria dado verde (para nåo mascarar o resultado) complementar, optamos pelo cálculo de 3\% de M.S. sobre o peso vivo do animal. Deste modo o esquema alimentar foi o seguinte.

\section{ALIMENTAÇAO}

\begin{tabular}{|c|c|c|c|c|}
\hline Dia & Raçáo & Manhă & Tarde & Cr203 \\
\hline $\begin{array}{l}05 / 07 / 1988 \\
06 / 07 / 1988 \\
07 / 07 / 1988\end{array}$ & $\begin{array}{l}\text { 1/3 Nutriequi } \\
\text { 1/3 Nutriequi } \\
\text { 1/3 Nutrequi }\end{array}$ & $\begin{array}{l}3.000 \mathrm{~g} \\
3.000 \mathrm{~g} \\
3.000 \mathrm{~g}\end{array}$ & $\begin{array}{l}3.0009 \\
3.0009 \\
3.0009\end{array}$ & $\begin{array}{l}2 g M+2 g I \\
2 g M+2 g I \\
2 g M+2 g T\end{array}$ \\
\hline $\begin{array}{l}08 / 07 / 1988 \\
09 / 07 / 1988 \\
10 / 07 / 1988 \\
\end{array}$ & $\begin{array}{l}\text { 1/2 Nutriequi } \\
1 / 2 \text { Nutriequi } \\
1 / 2 \text { Nutriequi }\end{array}$ & $\begin{array}{l}3.000 \mathrm{~g} \\
3.000 \mathrm{~g} \\
3.000 \mathrm{~g}\end{array}$ & $\begin{array}{l}3.0000 \\
3.0000 \\
3.0009\end{array}$ & $\begin{array}{l}2 g M+2 g T \\
2 g M+2 g T \\
2 g M+2 g T\end{array}$ \\
\hline $\begin{array}{l}1 / 107 / 1988 \\
12 / 07 / 1988 \\
13 / 07 / 1988 \\
\end{array}$ & $\begin{array}{l}2 / 3 \text { Nutriequi } \\
2 / 3 \text { Nutriequi } \\
\text { 2/3 Nutriequi }\end{array}$ & $\begin{array}{l}3.000 \mathrm{~g} \\
3.000 \mathrm{~g} \\
3.000 \mathrm{~g}\end{array}$ & $\begin{array}{l}3.0009 \\
3.0009 \\
3.0009\end{array}$ & $\begin{array}{l}2 g M+2 g T \\
2 g M+2 g T \\
2 g M+2 g T\end{array}$ \\
\hline $\begin{array}{c}15 / 07 / 1988 \\
a \\
22 / 07 / 1988\end{array}$ & $\begin{array}{l}\text { 3/3 Nutriequi } \\
\text { 3/3 Nutriequi }\end{array}$ & $\begin{array}{l}3000 \mathrm{~g} \\
3000 \mathrm{~g}\end{array}$ & $\begin{array}{l}3.000 \mathrm{~g} \\
3.000 \mathrm{~g}\end{array}$ & $\begin{array}{l}2 g M+2 g T \\
2 g M+2 g T\end{array}$ \\
\hline$M=$ Manhå & & & & $T=$ Tarde \\
\hline
\end{tabular}

** Ração Nutriequi Grĩos - Sul Mineira Alimentos S.A.

*** Composiçio: Mineral, Protécica e Vilamínica.

\section{Oxido crômico}

$O$ indicador $\mathrm{Cr} 203$ p.a. MERCK, era acondicionado em papel xarope e pesado rigorosamente em balança analítica Metler. Cada envelope contendo $2 \mathrm{~g}$ de $\mathrm{Cr} 203$ era, após prensado em peletizadora manual, reduzido a um grăo quase semelhante ao da raçaðo fornecida. Quando o alimento era fomecido $(3.000 \mathrm{~g}$ pela manhă e $3.000 \mathrm{~g}$ à tarde) a substância indicadora era administrada junto ao alimento. No total foram fornecidos 72 "pcllets" de óxido crômico para dois animais.

\section{Colheita de amostras}

Após o período de 13 dias, durante os quais os animais receberam a ração (já descrita), juntamente com 02 "pellets" de óxido crômico, $(4 \mathrm{~g})$ iniciou-se o período de colheila que teve duração de 5 dias. As excreçđes foram colhidas diretamente do reto do animal perfazendo um cotal de $\pm 500 \mathrm{~g}$. uma única vez ao dia. A recolha obedeceu o esquema seguinte:

a) amostras de 24 horas - apos a retirada das fezes do relo do animal, estas eram acondicionadas em frascos de bocia larga previamente pesados.

b) amostra do "total" - de cada período de 24 horas foram tomadas alíquotas $(10 \%)$ e colocadas em um frasco denominada de "total", que reccbeu as amosuras dos 5 dias do período experimental.

\section{Métodos analíticos}

As detcrminaçðoss de matéria seca (M.S.) proteina bruta, extrato etéreo e cinzas, foram feitas segundo os métodos oficiais da ASSOCIATION OF OFFICIAL AGRICULTURAL CHEMISTS $^{2}$ (1945), os carboidratos totais e a matéria orgânica obtidos por diferença.

O óxido crômico foi determinado sugerindo-se o método modificado por SCHURCK et al. ${ }^{15}$ (1950) e as leituras realizadas em espectrototômetro Zciss, modelo PMQII em comprimento de onda de 370 nanômetros.

\section{Métodos estatísticos}

Os valores percentuais antes dos tratamentos estatísticos, foram transformados em ângulos (ang + arc sen $\checkmark$ porcentagem, scgundo SNEDECOR' (1946); para avaliação final será usado o teste de F. como preconiza GOMES? (1963).

\section{RESULTADO E DISCUSSĀO}

A análise química da raçāo empregada, resultou nos dados encontrados na Tab. 2.

Na Tab. 3 estão contidos os Coeficientes de Digestibilidade (\%) da matéria seca obtidos pelos métodos de indicador extcrno, para os animais 1 e 2. 
TABELA 2

Composiçăo química da raçåo (\%). Săo Paulo, 1992.

\begin{tabular}{lc}
\hline Componentes brutos & Sobre M. Úmida \\
\hline Matéria Seca & 91,74 \\
$\mathrm{H}_{2} \mathrm{O}$ & 8,25 \\
Componentes brutos & Sobre M.Seca \\
Matéria orgânica & 91,74 \\
Proteina Bruta & 13,73 \\
Extrato Etéreo & 3,50 \\
Matéria Mineral & 8,26 \\
Fósioro & 0,43 \\
Cálcio & 1,73 \\
\hline
\end{tabular}

TABELA 3

Coeficientes de digestbilidade aparente (\%) da matéria seca, durante períodos sucessivos de horas e da colheita total (5 dias).Sảo Paulo, 1992.

\begin{tabular}{lcc}
\hline Dia & \multicolumn{2}{c}{ Animal } \\
\hline 1 & 1 & 2 \\
2 & 85,83 & 95,32 \\
3 & 88,17 & 95,22 \\
4 & 87,94 & 82,13 \\
5 & 89,42 & 87,48 \\
\hline Total & 90,43 & 87,78 \\
Média & 88,74 & 85,05 \\
Erro da média & 88,35 & 89,59 \\
CV\% & 1.3816 & 4.9700 \\
\hline
\end{tabular}

Os valores encontrados no total, 88,74 para o animal $n^{\circ} 1 \mathrm{e}$ 85,05 para o animal $n^{\circ} 2$, diferiram entre si. As médias encontradas 88,35 para o lote 1 é 89,59 lote I é 89,59 lote II năo foram significantes, apesar dos resultados do lote 2 , nos dias 1 e 2 respectivamente 95,32 e 95,22 serem mais altos que a média e total dos animais em questăo. Aliás, durante estes dois dias este animal apresentou ligeira indisposição, devido provavelmente ao fato de nāo ter acesso ao pátio para se exercitar.

Os valores médios do Coeficiente de Digestibilidade, obtidos nas amostras totais, mostraram-se concordantes com os conseguidos em ciclos de 24 horas, para os dois animais. Os valores encontrados por VEIGA et al." (1974) 46,2 a 50,8 e 39,3 a $44,8 \%$ ficaram bem abaixo dos valores aqui achados. Estes valores elevados confirmam os achados de OLSSON ${ }^{13}$ (1949) e MAYNARD et al.'2 (1984) de que a alimentação controlada eleva o coeficiente de digestibilidade, enquanto a "ad libitum" pode introduzir erros incontroláveis para a determinação da digestibilidade. Os dados do presente trabalho se assemelham aos de DARLOWGTON; HERSHBERGER ${ }^{3}$ (1968) em pôneis, e GLOVER; DUTHIE' ${ }^{6}$ (1958), bem como os de SKULMOUSKI' ${ }^{16}$ (1950) embora ainda mais elevados que estes últimos.

Os coeficientes de variaçăo foram bem baixos para os dois animais - 1,97 animal $n^{0} 1$ e 6,99 animal $n^{2} 2$ - se confrontando com os achados de VEIGA et al." (1974) (17,2 a 19\%) e $(17,4 \%$ e $15,2 \%)$ para dois lotes experimentais.

No presente caso o valor 6,99 deveu-se à ligeira indisposição encontrada nos dois primeiros dias de colheita para o animal $n^{2} 2$.

No relativo à aceitaçăo da raçæo, a palatabilidade foi amplamente comprovada pelos lotes em ensaio, desde o primeiro dia do periodo pré-preliminar. Este fato ajudou em muito a aceitaçăo do óxido crômico, que era ingerido juntamente com o alimento. $O$ espaço de tempo para estabulaçảo dos animais nåo deve ultrapassar 15 dias com as raçōes oferecidas. Após este pcríodo o apecite do animal $n^{\circ} 2$ diminuiu e o experimento conforme planejado foi encerrado. Outros experimentos e repeuçðes devem ser realizados.

\section{CONCLUSŌES}

Face às condiçð̋es em que se realizou o presente estudo, parecem lícitas as seguintes conclusoes:

1) Palatabilidade: A ração foi plenamente aceita pelos animais que consumiram 6 kilos diariamente durante 18 dias experimentais.

2) Os coeficientes de digestibilidade médios $(88.35$ e $89.59 \%$ ) revelaram um alto índice de aproveitamento da raçăo.

3) Os animais estabulados e sem exercício podem apresentar indisposiçðes digestivas, após 16 dias de estabulaçæo.

4) Outros ensaios, com administraçăo da raçăo e um pouco de verde, devem proporcionar condiçðes ideais para os animais.

\section{AGRADECIMENTOS}

Às Sras. Zeni Martins de Oliveira e Aparecida Vieira Gomes, pela manipulação das amostras.

\section{SUMMARY}

The applicability of the index substance - chromic oxide - to measure the palatability and digestibility, was studied with horses commercial diets in stabling condition. The animals were maintained in individual boxes and received ration containing $4 \mathrm{~g}$ of chromic oxide. The facces were quantitatively collected in 24 hours periods to oblain representative sample for 24 hours and 5 days total periods. The average digestibility coefficients $(88.35 \%$ and $89.59 \%$ ) showed a high level of ration utilization.

UNITERMS: Food digestibility; Animal feed; Horses

\section{REFERÊNCIAS BIBLIOGRÁFICAS}

01 -ANDREASI, F. Estudo comparativo sobre a aplicabilidade dos métodos do óxido crômico e convencional para a avaliaçảo da digestibilidade aparente no rato albino. II. Indices de retenção do nitrogênio, cálcio e fósforo, de ração comercial balanceada (Dog meal). Rev. Fac. Med. Vet., São Paulo, v.5, p.375-98, 1955.

02-ASSOCIATION OF OFFICIAL AGRICULTURAL CHEMISTS. Official and untauves method of analisis. 6.ed. Washington, 1945.

03-DARLINGTON, J.M.; HERSHBERGER, T.V. Effect of forage maturity on digestibility, intake and nutritive value of alfafa. timothy and orchard grass by equine. J. anIm. Scl., v.27. p.1572-6, 1968. 
04-EDIN el al. 1944 apud VEIGA, J.S.M.; ANDREASI, F.; PRADA, F.; MENDONÇA JUNIOR, C.X.'. p.7-20.

05-FRIEND, D.W.; NICHOLSON, J.W.C. Note on harneess and feces collection bag digestibility trial with horses. Canad. J. onIm. Sci., v.45, p.54-5, 1965.

06-GLOVER, J.; DUTHIE, D.W. The apparent digestibility of curde protein by non-ruminants and ruminants. J. agrlc. Scl., v.51. p.289-93, 1958.

07-GOMES, F.P. Curso de estatística experimental. 2.ed. Piracicaba, ESALQ, 1963.

08-HINTZ, H.F.; HOGUE, D.E.; WALKER JUNIOR, E.F.; LOWE, J.E.; SCHRYUER, H.F. Apparent digestion in segments of the digestive tract of ponies diets with variyng roughagegrain rations. J. anim. Scl., v.32, p.245-8, 1971.

09-HINTZ, H.F.; LOY, R.G. Effects of pelleting on the nutritive value of horses rations. J. anim. Sci., v.25, p.1059-62, 1966.

10-ITURBIDE, C.A. El 6́xido crômico como indicador externo para estimar producion fecal y consumo en la pruebas de digestibilidad. Turrialba, v.17, p.304-13, 1967.

11-KNAPKA, J.J.; BARTH, K.M.; BROWN, D.G.; CRAGLE, R.G. Evaluation of polyethylene, chromic oxide and ceriun - 144 as digestibility indicators in burros. J. Nutr., v.92, p.79-85, 1967.
12-MAYNARD, L.A.; LOOSLI, J.K.; HINTZ, H.F.; WARNER, R.G. Nutrição animal. 3.ed. Rio de Janeiro, Freitas Bastos, 1984.

13-OLSSON, $\mathbf{N}$. The ration between the organic nutrients of rations and their digestibility in horses. Ann. Roy. Agric. Coll. Sweden, v.16, p.644-69, 1949.

14-PULSE, R.E.; BEKER, J.P. Polyethilene and $\mathrm{Cr}_{2} \mathrm{O}_{3}$ retention in horses. J. anim. Scl., v.33, p.238, 1971.

15-SCHURCH, A.F.; LLOYD, L.E.; CRAMPTON, E.W. The use of chromic oxide as an index for determining the digestibility of diet. J. Nutr., v.41, p.629-36, 1950

16-SKULMOWSKI, J. Experiments on the determination of digestibility - Coeficients of some fodder - substitutes for horses. Ann. Univ. M. Curie, Sklodouska, v.5, n.22, p.13 27. 1950.

17-SNEDECOR, G.W. Statistical methods. 4.ed. Ames, lowa State Colege. 1946.

18-VEIGA, J.S.M.; ANDREASI, F.; PRADA, F.; MENDONÇA JUNIOR. C.X. Digestibilidade aparente da matéria seca em equilinos "1/2 Sangue Bretăo e 1/2 Sangue Inglês". Rev. Fac. Med. Vet. Zootec. UnIv. S. Paulo, v.11, p.7-20, 1974

Recebido para publicaçăo em 05/06/92 Aprovado para publicaça em $15 / 12 / 92$ 